\begin{tabular}{|c|l|}
\hline Title & The effect of patch demography on the community structure of forest trees \\
\hline Author(s) & Kohyama, T. \\
\hline Citation & $\begin{array}{l}\text { Ecological Research, 21/3), 346-355 } \\
\text { https://doi.org/10.1007/311284-006-0168-8 } 8\end{array}$ \\
\hline Issue Date & 2006-05 \\
\hline Doc URL & http://hdl.handle.net/2115/13477 \\
\hline Rights & The original publication is available at www.springerlink.com \\
\hline Type & article (author version) \\
\hline File Information & kohyama_ER.pdf \\
\hline
\end{tabular}

Instructions for use 
Ecological Research 21 (2006), in press

DOI 10.1007/s11284-006-0168-8

\section{The effect of patch demography on the community structure of forest trees}

Takashi Kohyama

Faculty of Environmental Earth Science, Hokkaido University, Sapporo 060-0810, Japan

Email: kohyama@ees.hokudai.ac.jp

Tel: +81.11 .706 .2260$

Fax: +81.11 .706 .4954$

And

Frontier Research Center for Global Change, Japan Agency for Marine-Earth Science and Technology, 3137-25 Showamachi, Kanazawa-ku, Yokohama 236-0001, Japan.

This manuscript is consisted of 25 pages of text including two tables, and 8 figures. Editorial correspondence to the above Sapporo address. 
Abstract The effect of patch demography on the structure of forest tree communities was examined using a patch-age, and tree-size structured model of forest dynamics. Changes in abundance of species of different types (four different maximum tree size classes each in two or three shade-tolerance classes) were numerically modeled in response to changes in the duration of the gap-formation-free lag phase. Average patch mortality was identical in all simulations. Tolerant species were more abundant without a lag phase due to larger variation in patch longevity, while subtolerant or intolerant species were successful when patch longevity was fixed with a long duration of the lag phase. Variation in patch age distribution facilitated species coexistence. Increasing 'advance regeneration', or surviving fraction at gap formation, brought about the exclusive dominance of tolerant species. Results suggest that patch demography plays a significant role in the community organization of forest trees. In species-rich systems like tropical rain forests, longevity, or canopy duration of large trees can differ among species, which brings about the variation in patch longevity, thus promoting further coexistence of species.

Key words Advance regeneration, Coexistence, Gap dynamics, Lag phase, One-sided competition, Patch mortality, Shade tolerance, Simulation 


\section{Introduction}

Simon Levin (Levin and Paine 1974; Levin 1976) introduced the theoretical framework of patch mosaic dynamics creating heterogeneous spatial patterns in the organization of biological communities. A simplified model distinguishing two dichotomous states of patches into either occupied or vacant has been widely applied (Levins and Culver 1971; Levin 1974, 1976; Whittaker and Levin 1977; Tilman 1994) and contributed to the concepts of meta-population and meta-community (Gilpin and Hanski 1991). Meanwhile, it is possible to observe finer-scale resolution of the states of patches, such as patch age and size. To study these dynamics, Simon Levin suggested the use of the continuity equation of fluid dynamics in physics. For instance, ignoring the patch-size dimension, the dynamics of the probability for a patch at age $a$ at time $t, s(t, a)$, is described by

$\frac{\partial s(t, a)}{\partial t}=-\frac{\partial s(t, a)}{\partial a}-\gamma(a) s(t, a)$

where $\gamma(a)$ is age-specific mortality of patches. If the total land area is conserved and 'dead' patches simultaneously contribute to the creation of 'newborn' patches, the boundary condition of Eq (1) with respect to patch age $a$ is described as

$s(t, 0)=\int_{0}^{\infty} \gamma(a) s(t, a) d a$.

The model of Eqs (1) and (2) allows us to develop demographic analyses of patch dynamics in a landscape on which species migrate, persist and reproduce. Patch mortality in ecological systems can be dependent on the state of the patches. For 
instance, in forest ecosystems prone to disturbances such as fire, prevailing wind, storm, and landslide, the probability of damage by disturbance is often dependent on the developmental stage of patches, and is usually higher at later stages of patch development where patches have higher fuel stock, higher canopy stature, and heavier deposition of topsoil with aboveground vegetation load (Heinselman 1973; Sprugel 1976; Kohyama and Fujita 1981; Johnson and Van Wagner 1984; Foster 1988; Clark 1989). It is not known how the pattern of patch survival influences tree community structure.

In this paper, I examine how patch demography affects the landscape pattern and tree community structure of forest ecosystems, applying a model of forest dynamics (Kohyama 1993) which combines patch demography model of Eqs (1) and (2) and the dynamic model of tree size structure regulated by patch-scale upper crowding (Kohyama 1992). Kohyama (1993) suggested by model analysis that the stable coexistence among tree species is enabled by one-sided competition among trees (vertical light-resource heterogeneity) and is further emphasized by among-patch variation in crowding (horizontal heterogeneity) through among-species trade-offs in demographic parameters, proposing "forest architecture hypothesis" of tree species coexistence. Using the same model, Kohyama (1997) showed that the increasing growth rate of individual trees, and the decreasing tree mortality and gap formation rate promote species coexistence, by creating larger spatial light-resource heterogeneity. However, the effect of changing patch demography on tree communities has not been examined so far.

In this paper, using basically the same model of Kohyama (1993), I show how community structure is sensitive to the patch demographic patterns even while keeping the average patch mortality identical. I also show how large the effect of advance regeneration, or the survived fraction through gap formation process, on the community structure of forest trees. 


\section{Methods}

The model

I assume that a forest is composed of patches of different ages since gap formation. Tree population dynamics are regulated at the local scale of the patch, and across-patch interactions occur through patch aging, patch mortality, and reproduction of populations with random seed dispersal across patches. Establishment and recruitment of tree populations are not restricted to gaps, or newborn patches, but occur in patches of any age. Further if there are survivors at gap formation, patches of age zero can contain various-aged trees. Therefore, patch age is not a good predictor of tree age in this model system, as well as in actual forests.

I employ the same model as in Kohyama (1993) for patch demography, where patch mortality, or gap formation rate, is described by a function of patch age $a, \gamma(a)$ $\left(\right.$ year $\left.^{-1}\right)$. I assume that gap formation does not occur for the period from patch age zero to patch age $a_{\mathrm{c}}$ (lag phase duration), and is constant afterwards:

$$
\begin{array}{ll}
\gamma(a)=0 & \text { for } a \leq a_{\mathrm{c}} \\
\gamma(a)=1 /\left(L-a_{\mathrm{c}}\right) & \text { for } a>a_{\mathrm{c}} .
\end{array}
$$

From Eq (3), the cumulative probability for a patch to survive from age 0 to $a, l(a)$, is 1 for $a \leq a_{\mathrm{c}}$, and is an exponential function

$$
l(a)=\exp \left(-\int_{0}^{a} \gamma(\alpha) d \alpha\right)=\exp \left(-\frac{a-a_{\mathrm{c}}}{L-a_{\mathrm{c}}}\right) \quad \text { for } a>a_{\mathrm{c}}
$$

of which average longevity from the age of $a_{\mathrm{c}}$ is $L-a_{\mathrm{c}}$ (year). Therefore, $L$ (year) is 
average patch duration, and $1 / L\left(\right.$ year $\left.^{-1}\right)$ is average patch mortality or gap formation rate, for the whole forest landscape irrespective of $a_{\mathrm{c}}$ 's. Figure 1 shows the dependence of $l(a)$ on changing lag phase duration, $a_{\mathrm{c}}$. Variation in patch demography in this paper is introduced by changing $a_{\mathrm{c}}$ as in Fig. 1, setting $L$ at 100 (years). Kohyama (1993) used $a_{\mathrm{c}}=40$ and $L=100$ (years) as default, based on the analysis of basal-area dynamics of a warm-temperate rain forest (Kohyama 1987).

I define the word 'landscape' as the closed space, without any reproductive input from outside, consisting of patches of various ages. Distribution of tree population of species $i$ in size in trunk diameter $x(\mathrm{~cm})$ and patch age $a$ at time $t$ (year) throughout the landscape is denoted $f_{i}(t, a, x)\left(\mathrm{cm}^{-1} \mathrm{~m}^{-2} \operatorname{year}^{-1}\right)$. Dynamics of $f_{i}(t, a, x)$ is described by (cf. Kohyama 1993)

$$
\frac{\partial f_{i}(t, a, x)}{\partial t}=-\frac{\partial f_{i}(t, a, x)}{\partial a}-\frac{\partial\left(G_{i}(t, a, x) f_{i}(t, a, x)\right)}{\partial x}-\left(\gamma(a)+\mu_{i}(t, a, x)\right) f_{i}(t, a, x),
$$

where $G_{i}(t, a, x)\left(\mathrm{cm} \mathrm{year}^{-1}\right)$ is growth rate of tree size $x$ of species $i$ at a patch of age $a$ at time $t, \gamma(a)\left(\right.$ year $\left.^{-1}\right)$, the same as in Eqs (1)-(3), is the mortality of a patch at age $a$ due to gap formation, and $\mu_{i}(t, a, x)$ (year $\left.{ }^{-1}\right)$ is gap-formation-free mortality of tree at size $x$ at a patch of age $a$ at time $t$,. The dynamics is restricted by boundary conditions with respect to $a$ (advance regeneration) and $x$ (reproduction) given respectively by

$$
\begin{aligned}
& f_{i}(t, 0, x)=p(x) \int_{0}^{\infty} \gamma(a) f_{i}(t, a, x) d a, \\
& G_{i}\left(t, a, x_{0}\right) f_{i}\left(t, a, x_{0}\right)=R_{i}(t) s(t, a),
\end{aligned}
$$

where $p(x)$ (dimensionless) is the tree-size-dependent probability of survival through a gap formation event, $R_{i}(t)\left(\mathrm{m}^{-2}\right.$ year $\left.^{-1}\right)$ is landscape-level reproduction of species $i$, and $s(t, a)\left(\right.$ year $\left.^{-1}\right)$ is the landscape-level probability for a patch at age $a$ at time $t$ as in Eq (1), 
and $x_{0}$ is the minimum tree size for recruitment. The sub-model of tree population dynamics, Eqs (5)-(7), is combined with the sub-model of patch age dynamics, Eqs (1) and (2), sharing gap formation rate $\gamma(a)$, to describe the overall dynamics (Kohyama 1993; Hurtt et al. 1998; Kohyama et al. 2001; Moorcroft et al. 2001).

A strong assumption of the model is that all of three demographic processes of growth, mortality and reproduction for the tree at size $x$ are regulated by the local upper basal area $B(t, a, x)\left(\mathrm{cm}^{2} \mathrm{~m}^{-2}\right)$, that is basal area per patch of age $a$ above size $x$ for all species:

$$
B(t, a, x)=\frac{\pi}{4 s(t, a)} \sum_{i} \int_{x}^{\infty} y^{2} f_{i}(t, a, y) d y
$$

This assumption is based on the unique property of light competition among forest trees, such that upper trees absorb light resources first, and lower trees exploit leftovers penetrated through upper canopy. The other important aspect of this assumption is that there is no species-to-species specific factor that modifies the strength of inter-specific competition, which are on the contrary the basis for the stable coexistence of species in no-stage-structured models such as the Lotka-Volterra competition equations.

Size growth rate $G_{i}(t, a, x)$ is formulated by

$G_{i}(t, a, x)=b_{i} x\left(1-b_{1 i} \ln x-b_{2 i} B(t, a, x)\right)$,

for non-negative $G_{i}(t, a, x)$; otherwise $G_{i}(t, a, x)=0$ (Kohyama 1992, 1993). Three parameters of Eq (9) characterize tree growth properties. Parameter $b_{i}\left(\mathrm{~cm} \mathrm{year}^{-1}\right)$ is the potential relative growth rate of a tree of species $i$, where potential means that for trees at $x=1 \mathrm{~cm}$ without upper crowding $B(t, a, x)=0$. Parameter $b_{1 i}\left([1 \mathrm{n} \mathrm{cm}]^{-1}\right)$ describes the degree of size-dependent decline of relative growth rate, and $\exp \left(1 / b_{1 i}\right)(\mathrm{cm})$ 
characterizes the upper maximum size of species $i$ where growth rate is zero. The third parameter $b_{2 i}\left(\mathrm{~m}^{2} \mathrm{~cm}^{-2}\right)$ is the degree of sensitivity to upper crowding in relative growth rate.

Mortality in this model, as in Eq (5), is composed of disturbance-caused mortality $\gamma(a)$ and thinning-caused mortality $\mu_{i}(t, a, x)$. Disturbance-caused mortality $\gamma(a)$ is linked with patch demography and is independent of tree size $x$ in the case without advance regeneration. Gap formation is caused by the mortality of canopy trees and there may be a fraction of trees that survive through gap formation to form advance regeneration. Survival during gap formation is likely to decrease with increasing tree size. Probability of survival to form advance regeneration, $p(x)$ in Eq (6), is expressed as a decreasing function with size $x$,

$$
p(x)=\frac{k}{k+x}
$$

for non-negative $k(\mathrm{~cm})$. In this equation, $k=0$ means no advance regeneration, and $k=$ 1 and 4 to allow respectively $p(x)=1 / 3$ and $2 / 3$ survival for trees at the minimum size of $x=2 \mathrm{~cm}$ in the present simulation, while almost no trees survive $(0.7$ and $2.6 \%)$ at the model-parameter defined maximum size of $x=150 \mathrm{~cm}$.

Mortality due to thinning by local crowding, $\mu_{i}(t, a, x)$, is assumed here to be proportional to $B(t, a, x)$, with species-specific parameter of sensitivity to upper crowding in mortality, $c_{i}\left(\mathrm{~m}^{2} \mathrm{~cm}^{-2}\right.$ year $\left.^{-1}\right)$. To make results comparable across simulated systems with changing $k$, operational 'thinning' corresponding to advance-regeneration, $p(x) \gamma(a)$, is added to the mortality by crowding as

$$
\mu_{i}(t, a, x)=c_{i} B(t, a, x)+p(x) \gamma(a) .
$$


Reproduction of a tree of species $i$ at size $x$ at a patch of age $a, r_{i}(t, a, x)\left(\operatorname{tree}^{-1}\right.$ year $\left.{ }^{-1}\right)$ is assumed to be proportional to its own basal area, $\pi x^{2} / 4\left(\mathrm{~cm}^{2}\right)$, and is suppressed by local upper basal area of the patch as

$r_{i}(t, a, x)=d_{i} \frac{\pi}{4} x^{2}\left(1-d_{1 i} B(t, a, x)\right)$

for non-negative $r_{i}(t, a, x)$; otherwise $r_{i}(t, a, x)=0$. Parameter $d_{i}\left(\mathrm{~cm}^{-2}\right.$ year $\left.{ }^{-1}\right)$ describes annual seed reproduction rate per basal area of a tree of species $i$, and parameter $d_{1 i}\left(\mathrm{~m}^{2}\right.$ $\mathrm{cm}^{-2}$ ) expresses the sensitivity to local upper crowding in reproduction of species $i$. Landscape-level reproduction of species $i, R_{i}(t)$, is therefore

$R_{i}(t)=\int_{0}^{\infty} \int_{x_{0}}^{\infty} r_{i}(t, a, x) f_{i}(t, a, x) d x d a$

and is assumed to be randomly dispersed across patches over the landscape as in Eq (7). This expression of reproduction is different from that in Kohyama (1993) where 'recruitment' rate as the mixture of seed production process and seedling survival/upgrowth processes is expressed only by the total basal area of the patch due to the limitation of forest-plot census data. Here, I employ more precise Eq (12) based on single-tree reproduction process, where light availability, expressed by local upper crowding, determines reproduction rate of a single tree (cf. Kohyama 1982; Greene et al. 2002; Uraguchi and Kubo 2005). 
Simulation

Eight or twelve species differing in potential maximum tree size in four layers and in two (or three) shade-tolerance classes of either tolerant, (subtolerant) or intolerant were modeled. Their demographic parameters, except reproductive capacity $d_{i}$, were arbitrarily chosen to reflect the observed values for warm-temperate rain forest (Kohyama 1992, 1993), as shown in Table 1. Potential maximum size, or $\exp \left(1 / b_{1 i}\right)$, is respectively $148.8,46.8,22.8$ and $12.2 \mathrm{~cm}$ for canopy, subcanopy, understorey and treelet species. Subtolerant and intolerant species are respectively twice and three-times more sensitive to the crowding than tolerant species in growth $\left(b_{2 i}\right)$, mortality $\left(c_{i}\right)$ and reproduction $\left(d_{1 i}\right)$, and are respectively two- and three-times higher in potential size growth rate $\left(b_{i}\right)$ than tolerant species. The left parameter $d_{i}$ was then tuned for the eight species (in two tolerance classes) or the twelve species (in three tolerance classes) to allow them to coexist in respective three conditions of patch demography, namely 0,40 and 90 years of lag phase defined by $a_{c}$.

Simulation runs using a finite-difference approximation method were carried out with 1-year time steps, $\Delta t$, up to 40,000 years (until system attained steady state), 10 -year intervals for patch age, $\Delta a$, up to 400 years with a pooled age class of above 400 years, and $2-\mathrm{cm}$ for tree size, $\Delta x$, with the minimum size of $x_{0}=2 \mathrm{~cm}$. Initial condition at time $t=0$ was 0.001 tree $\mathrm{m}^{-2}$ for each species at the minimum size class of each patch age class from 0 to 100 years. Simulation suggests that the longtime steady state is independent of initial conditions. Source code of simulation in c++ is available at http://hosho.ees.hokudai.ac.jp/ kohyama/Gmodel/.

I examined community sensitivity to a variety of situations, by comparing steady-state community structure in species abundance, after 40,000 years of simulation, across situations. Examined situations were (i) changing reproduction capacity for a particular species, (ii) changing patch demography, in terms of lag phase duration $a_{\mathrm{c}}$, 
from 0 to 90 years at 10-year intervals, and (iii) changing the degree of advance regeneration, in terms of $k$ from 0 to 5 at intervals of 0.5 .

\section{Results}

The case with eight species

\section{Tuning and simulation for species coexistence}

I tuned the reproduction parameters, $d_{i}$, left free with fixed set of other parameters in Table 1 so that all of the eight species (four stature classes in each of two tolerance classes, without subtolerant class) eventually coexisted over 40,000 years, for each of lag phases of 0,40 and 90 years in patch demography without advance regeneration $(k=$ 0 ), with $d_{i}$ of intolerant-treelet species identical throughout. The tuned $d_{i}$ for coexistence, in the left three columns of Table 2, differed among scenarios of patch dynamics with different lag phases. Tolerant species with small reproductive capacity (defined by $d_{i}$ ) persisted and coexisted with intolerant species in patch dynamics with short lag phases while high reproductive capacity was required for persistence of tolerant species with intolerants in long lag-phase conditions. Low-stature intolerant species needed to have high reproductive capacity in short lag-phase patch demography to coexist with tolerant species. Each single species, without competitors, defined by Tables 1 and 2 persisted over any patch demography with changing lag phase $\left(0 \leq a_{c}<\right.$ $L)$ and changing the fraction of advance regeneration $(0 \leq k \leq 5)$. It is because the per capita reproduction rate exceeded mortality without thinning, and the intrinsic growth rate was positive.

Figure 2 illustrates the time course of the eight-species systems for $a_{c}=0,40$, and 90 years. Abundance of each species is expressed by landscape-level species basal 
area,

$B_{0 i}=\frac{\pi}{4} \int_{0}^{\infty} \int_{x_{0}}^{\infty} x^{2} f_{i}(t, a, x) d x d a$,

on vertical axes in Fig. 2, and in Figs 4-8 as well.

Irrespective of lag-phase difference, intolerant species occupied the landscape first and tolerant species followed replacing intolerants (Fig. 2). Time required for the community to attain steady state changed from a few thousand years for $a_{c}=0$ (Fig. 2a) to several thousand years for $a_{\mathrm{c}}=40$ (Fig. 2b), and to several ten thousand years for $a_{c}=$ 90 (Fig. 2c). Particularly for $a_{c}=90$, such long time of 40,000 years was not sufficient for the system to attain steady state, as the abundance of tolerant subcanopy species was slowly but steadily declining until the simulation year 40,000 (Fig. 2c). At the 'steady state' (or exactly at the final simulation year 40,000), overall coverage was increased with patch age, and species abundance was dependent on patch age (Fig. 3). Intolerant species were more abundant in younger patches and persisted in aged patches. Tolerant species abundance increased in older patches. Within each tolerance class, canopy species increased their abundance in older patches as compared to lower-statured species.

\section{Sensitivity to changing reproduction capacity}

Demographic parameters of each species substantially affected the steady-state community structure. Figure 4 illustrates examples of changing reproduction parameter $d_{i}$ of tolerant canopy species, for each of three lag-phase scenarios, from $1 / 5$ to 2 times of baseline figure in Table 2. Change in community structure with single-species reproduction parameter was most remarkable for long lag phase case (Fig. 4c); by contrast it was relatively moderate for no lag phase case (Fig. 4a). Decreasing $d_{i}$ for 
tolerant canopy species brought about the failure of not only tolerant canopy, but also tolerant understory, and increasing it resulted in the marked decline of tolerant subcanopy and understory, more than treelet class (Fig, 4a, b).

The change in competitive ability of a particular species largely influenced to nearby-stature species at the same tolerance class, and was indirectly influenced to more different species in stature and tolerance. Interesting situations demonstrated in Fig. 4a, $\mathrm{b}$ are that the addition of one species (tolerant-canopy species, in this case) into the system without it promotes the survival and coexistence of another species (tolerant-understorey species) that is excluded by competition with other species (tolerant-subcanopy and tolerant-treelet species) as in the left end of Fig. 4a, b.

\section{Sensitivity to changing lag phase}

With increasing the duration of lag phase in patch demography for the each of species parameter sets, the overall steady-state coverage decreased and so for the abundance of tolerant species, from higher stature to lower in sequence (Fig. 5). A long lag phase with small fraction of old patches (Figs 1 and 3) still offered habitats for shade-tolerant, low-stature species, as the upper canopy of intolerant species created shaded conditions underneath. Similar to changing species reproductive capacity (Fig. 4), the tendency that species with apart statures to coexist was observed, for intolerant subcanopy and treelet in Fig. 5a right-end, tolerant canopy and treelet in Fig. 5b left-end, and intolerant canopy and treelet in Fig. 5c left-end.

\section{Sensitivity to changing advance regeneration}

With increasing survival of trees at gap formation, intolerant species decreased their abundance (Fig. 6). The decline in abundance of intolerant species group was emphasized by the long lag-phase case (Fig. 6c); intolerant species persisted even with high survival of small trees at gap formation for patch mortality of no lag phase (Fig. 
6a). Demography without lag phase provided opportunity for four tolerant species sharing stature classes to coexist (Fig. 6a). Intermediate lag phase brought about the failure of tolerant subcanopy species (Fig. 6b), and long lag phase demography eventually wiped out any other than tolerant canopy species (Fig. 6c) when advance regeneration increased.

The case with twelve species

\section{Tuning and simulation for species coexistence}

When intermediate tolerance class was added, twelve species characterized by four maximum stature classes and three tolerance classes (Table 1) coexisted in the patch demography of no lag phase, with tuned $d_{i}$ 's in the far right column of Table 2. It was however too subtle, or too narrow in parameter range, for their coexistence in longer lag-phase demography. Therefore, here demonstrates only the case with zero lag phase.

Figure 7 illustrates the time change of the community structure of the twelve species system. Intolerant species first increased their abundance, followed by subtolerant species bringing about temporal decline of intolerant abundance, at around year 1,000. Tolerant species finally increased, and the system converged to stable community structure after around ten-thousand years.

\section{Sensitivity to changing lag phase and advance regeneration}

Increasing lag phase duration in patch demography brought about the decline of both tolerant and intolerant species, and the forest with 90 years of lag phase was composed only of subtolerant subcanopy, subtolerant treelet, and intolerant subcanopy species (Fig. 8a). Increasing survival of small trees at gap formation resulted in the decline of intolerant species first, followed by the decline of subtolerant species. Within the same 
tolerance class, there was the tendency for lower stature species to disappear prior to the decline of higher stature species (Fig. 8b).

\section{Discussion}

The present results suggest that the pattern of patch demography in terms of variation of lag-phase duration of patch mortality substantially affects not only the overall ecosystem structure (in terms of total basal area) but also the composition and abundance of tree species. The case of patch-age independent patch mortality without lag phase provides a wider range of patch age distribution than other cases with lag phases (Figs 1 and 3). Therefore it is a reasonable result that tolerant species, particularly with large maximum stature, increased their abundance with decreasing duration of the lag phase. At the same time, in all the scenarios there existed young patches allowing intolerant species to persist in these less-crowded conditions.

Kohyama (1993) pointed out the mechanisms of stable coexistence among species simulated in this model: partial vertical segregation of species with different maximum stature mediated by one-sided regulation of size-structured populations at local patch scale, and among-patch segregation of species with different shade-tolerance at landscape scale. The present results additionally suggest that the demographic pattern without the lag phase provides the highest opportunity for species coexistence compared to that with long lag phase, because among-patch variation in crowding is highest for the no-lag-phase patch demography. Species difference in terms of reproductive capacity for coexistence was the largest (Table 2) and time for convergence in steady state was the shortest (Fig. 2) for no-lag-phase scenario. Changing species parameters least affected the community structure, for baseline no-lag-phase community (Fig. 4). Higher among-patch heterogeneity in structure 
provides greater opportunity for species to differentiate with respect to crowding conditions. Similarly, increasing advance regeneration least affected the coexistence of intolerant species with tolerant species in no-lag phase demography. It is also the high among-patch heterogeneity that makes it possible for species partitioning among three tolerant classes (Fig. 7).

Kohyama (1997) suggested, in the patch-heterogeneity ignored model (cf. Kohyama 1992), that possible range of reproduction parameter for a species to coexist with others was narrower when maximum statures between species were closer, and when the number of species was increased. Similarly, the present results suggest that the possible range of reproduction parameter is narrower in long lag phase, less heterogeneous patch demography, and is particularly so when the number of species is increased.

It is noteworthy that the present results (Fig. 4) demonstrate examples that adding a new species A into the multi-species system can cause not only the failure of some other species but also the recovery of another species B that is otherwise excluded by competition in the system without species A. Such case that a key stone species enables the coexistence of other two or more species has been recognized as the effect of third parties of community organization (Grubb 1986). The present results give the theoretical basis for the third party effect within autotrophs.

This study showed that the stable coexistence of twelve species, differing in their maximum stature and shade tolerance, was feasible in no-lag-phase case; however whether twelve is almost the realistic maximum of species packed along stature-tolerance axes or not is not yet known. This paper pre-assumed Table 1 parameters systematically, where species with different stature had the identical response to crowding, in terms of intrinsic growth rate, and tolerances in growth rate, survival and reproduction. However, it is likely to exist some interaction between shade tolerance and stature. Compared to high stature species, low stature species experience 
more shaded conditions. Also unknown is whether response to crowding is identical across growth rate, survival and reproduction. For instance, from forest permanent-plot census, the dependence to crowding is relatively easy to be recorded for growth rate, while is difficult for survival, and is impossible for individual-based reproduction. Identical maximum stature parameters across tolerance classes, and identical survival parameters across maximum stature classes at the same tolerant class (Table 1) may also make it difficult for species to coexist. The present trial of adjusting a single parameter of reproductive capacity (Table 2) may increase the difficulty for species to coexist. Further numerical and theoretical examination of community consequences of the changing of six demographic parameters for each species is needed, together with reliable field data analysis (Clark et al. 2003).

There are remarks suggesting that high frequency of disturbance, or gap formation rate, contributes to high species diversity in tropical rain forests (Connell 1978; Hartshorn 1978). Reported gap formation rate is however not remarkably different between tropical and extra-tropical forests (Denslow 1987; Kohyama 1997). On the contrary, examination using the same model as this paper, Kohyama (1997) suggests that high tree growth rate promotes but high tree mortality inhibits species coexistence. The present results suggest that even with the same average gap formation rate, patch-age-specific pattern of gap formation greatly contribute to the capacity of species coexistence.

A variety in the probability of survival among canopy tree species in species-rich forests may bring about a variation in canopy duration. Therefore, it is possible for species-rich tropical rain forests to show higher variation in canopy duration. Opposite cases are observed in wave-regenerated high altitude fir forests with almost fixed canopy duration (Sprugel 1976, Kohyama and Fujita 1981) and fire-regenerated sub-arctic forests (Heinselman 1973; Johnson and Van Wagner 1984), dominated only by a few canopy species. Variation in canopy duration and tree species 
diversity can be mutually interrelated.

The present model assumes that patch dynamics is dependent only on patch age, and is independent of the local community structure as a first-order approximation. However, patch mortality is likely to be dependent on local community structure. It is possible improvement to interrelate between sub-model of patch age dynamics and that of dynamics of population structure in tree size and patch age for all species.

This paper suggests the importance of recording patch-state specific gap formation rate in field census, in addition to the conventional estimation of landscape-average of gap formation rate. For instance, spatially explicit records from large-scale permanent plots enable the objective subdivision of patches to different coverage, or basal area, and the estimation of coverage-specific gap formation rate. Such information will contribute to the parameter estimation of patch demography, and to further understanding of tree community organization.

\section{Acknowledgments}

This paper is dedicated to Simon Levin in memory of his winning 2005 Kyoto Prize in Basic Sciences; I acknowledge his longtime warm encouragement. I also thank Yoh Iwasa, Takuya Kubo, Matthew Potts, Takenori Takada, Akio Takenaka and anonymous reviewers for their constructive suggestions on earlier manuscripts. 


\section{References}

Clark JS (1989) Ecological disturbance as a renewal process: theory and application to fire history. Oikos 56:17-30

Clark JS, Mohan J, Dietze M, Ibanez I (2003) Coexistence: how to identify trophic trade-offs. Ecology 84:17-31.

Connell JH (1978) Diversity in tropical rain forests and coral reefs. Science 199:1302-1310

Denslow JS (1987) Tropical rainforest gaps and tree species diversity. Annu Rev Ecol Syst 18:431-451

Foster DR (1988) Species and stand response to catastrophic wind in central New England, USA. J Ecol 76:135-151

Giplin M, Hanski I, ed (1991) Metapopulation dynamics: empirical and theoretical investigations. Academic Press, London

Greene DF, Messier C, Asselin H, Fortin MJ (2002) The effect of light availability and basal area on cone production in Abies balsamea and Picea glauca. Can J Bot $80: 370-277$

Grubb PJ (1986) The ecology of establishment. In: Bradshaw AD, Goode DA, Thorp E (ed) Ecology and design in landscape (Symposia of The British Ecological Society 24). Blackwell Sci Publ, Oxford, pp 83-97

Hartshorn GS (1978) Tree falls and tropical forest dynamics. In: Tomlinson PB, Zimmerman MH (ed) Tropical trees as living systems. Cambridge Univ Press, Cambridge, pp 617-638

Heinselman ML (1973) Fire in the virgin forests of the Boundary Waters Canoe Area, Minnesota. Quat Rev 3:329-382

Hurtt GC, Moorcroft PR, Pacala SW, Levin SA (1998) Terrestrial models and global change: challenges for the future. Global Change Biol 4:581-590 
Johnson EA, Van Wagner CE (1984) The theory and use of two fire history models. Can J For Res 15:214-220

Kohyama T (1982) Studies on the Abies population of Mt. Shimagare II. Reproductive and life history traits. Bot Mag Tokyo 95:167-181

Kohyama T (1987) Stand dynamics in a primary warm-temperate rain forest analyzed by diffusion equation. Bot Mag Tokyo 100:305-317

Kohyama T (1992) Size-structured multi-species model of rain forest trees. Funct Ecol 6:206-212

Kohyama T (1993) Size-structured tree populations in gap-dynamic forest: the forest architecture hypothesis for the stable coexistence of species. J Ecol 81:131-143

Kohyama T (1997) The role of architecture in enhancing plant species diversity. In: Abe T, Levin SA, Higashi M (ed) Biodiversity: an ecological perspective. Springer, New York, pp 21-33

Kohyama T, Fujita N (1981) Studies on the Abies population of Mt. Shimagare I. Survivorship curve. Bot Mag Tokyo 94:55- 68

Kohyama T, Suzuki E, Partomihardjo T, Yamada T (2001) Dynamic steady state of patch-mosaic tree size structure of a mixed dipterocarp forest regurated by local crowding. Ecol Res 16:85-98

Levin SA (1974) Dispersion and population interactions. Amer Nat 168:207-228

Levin SA (1976) Population dynamic models in heterogeneous environments. Annu Rev Ecol Syst 7:287-311

Levin SA, Paine RT (1974) Disturbance, patch formation, and community structure. Proc Nat Acad Sci USA 71:2744-2747

Levins R, Culver D (1971) Regional coexistence of species and competition between rare species. Proc Nat Acad Sci USA 68:1246-1248

Moorcroft PR, Hurtt GC, Pacala SW (2001) A method for scaling vegetation dynamics: the ecosystem demography model (ED). Ecol Monogr 71:557-586 
Paine RT, Levin SA (1981) Intertidal landscapes: disturbance and the dynamics of pattern. Ecol Monogr 51:145-178

Sprugel DG (1976) Dynamic structure of wave-regenerated Abies balsamea forests in the north-eastern United States. J Ecol 64:889-911

Tilman D (1994) Competition and biodiversity in spatially structured habitats. Ecology $75: 2-16$

Whittaker RH, Levin SA (1977) The role of mosaic phenomena in natural communities. Theor Popul Biol 12:117-139.

Uraguchi A, Kubo T (2005) Responses to light in individual growth and reproduction of two Acer species and the long-term consequences. Ecol Res 20:177-187 
Table 1 Demographic parameters of tree species populations, except $d_{i}$, defining four stature classes by three tolerance classes

Species

Tolerant-canopy

Tolerant-subcanopy

Tolerant-understory

Tolerant-treelet

Subtolerant-canopy

Subtolerant-subcanopy

Subtoleant-understory

Subtolerant-treelet

Intolerant-canopy

Intolerant-subcanopy

Intolerant-understory

Intolerant-treelet

$$
\begin{array}{ccccc}
b_{i} & b_{1 i} & b_{2 i} & c_{i} & d_{1 i} \\
\mathrm{~cm} \mathrm{y}^{-1} & {[\mathrm{ln} \mathrm{cm}]^{-1}} & \mathrm{~m}^{2} \mathrm{~cm}^{-2} & \mathrm{~m}^{2} \mathrm{~cm}^{-2} \mathrm{y}^{-1} & \mathrm{~m}^{2} \mathrm{~cm}^{-2}
\end{array}
$$

$\begin{array}{lllll}0.04 & 0.20 & 0.005 & 0.0001 & 0.005 \\ 0.04 & 0.26 & 0.005 & 0.0001 & 0.005 \\ 0.04 & 0.32 & 0.005 & 0.0001 & 0.005 \\ 0.04 & 0.40 & 0.005 & 0.0001 & 0.005\end{array}$

$\begin{array}{lllll}0.08 & 0.20 & 0.010 & 0.0002 & 0.010 \\ 0.08 & 0.26 & 0.010 & 0.0002 & 0.010 \\ 0.08 & 0.32 & 0.010 & 0.0002 & 0.010 \\ 0.08 & 0.40 & 0.010 & 0.0002 & 0.010\end{array}$

$\begin{array}{lllll}0.12 & 0.20 & 0.015 & 0.0003 & 0.015\end{array}$

$\begin{array}{lllll}0.12 & 0.26 & 0.015 & 0.0003 & 0.015\end{array}$

$\begin{array}{lllll}0.12 & 0.32 & 0.015 & 0.0003 & 0.015\end{array}$

$\begin{array}{lllll}0.12 & 0.40 & 0.015 & 0.0003 & 0.015\end{array}$ 
Table 2 Tuned reproduction parameter $d_{i}\left(\mathrm{~cm}^{-2} \mathrm{year}^{-1}\right)$ for eight and twelve species to coexist at each demographic conditions without advance regeneration; with respect to other parameters in Table 1

Species

Tolerant-canopy

Tolerant-subcanopy

Tolerant-understory

Tolerant- treelet

Subtolerant-canopy

Subtolerant-subcanopy

Subtoleant-understory

Subtolerant-treelet

Intolerant-canopy

Intolerant-subcanopy

Intolerant-understory

Intolerant-treelet $d_{i}$ of 8 species for

$$
a_{\mathrm{c}}=0 \quad a_{\mathrm{c}}=40 \quad a_{\mathrm{c}}=90
$$

0.0001

0.0005

0.001

0.0012

0.0005

$\begin{array}{lll}0.0012 & 0.002 & 0.002\end{array}$

0.0012

$\begin{array}{lll}0.0024 & 0.0035 & 0.0032\end{array}$

0.0024

0.00012

0.0015

0.005

0.011

0.00012

0.0024

0.010

$\begin{array}{lll}0.010 & 0.009 & 0.008\end{array}$

0.026 


\section{Figure legends}

Fig. 1 Patch survivorship curve, Eq (4), with changing the duration of lag phase, $a_{\mathrm{c}}$, from 0 to 90 years at 10 -year intervals. Average patch longevity $L$ is set at 100 years.

Fig. 2 Simulated time course of eight species abundance in basal area $B_{0 i}$. Panels a, b, c are respectively for patch demography with lag phase of 0,40 , and 90 years, using corresponding reproductive capacity parameters in Table 2. Shaded and open are respectively tolerant and intolerant species. The four species' stature classes, canopy, subcanopy, understory and treelet, are arranged from top to bottom for each of tolerance classes. No advance regeneration at gap formation.

Fig. 3 Steady-state distribution of species across the age of patches. Panels a, b, c are respectively for patch demography with lag phase of $0,40,90$ years, with corresponding reproductive capacity parameters in Table 2 . Shaded and open are respectively tolerant and intolerant species. The four species' stature classes of canopy, subcanopy, understory and treelet are arranged from top to bottom. Relative frequency of patch at 10 -year age class in broken line. No advance regeneration at gap formation.

Fig. 4 Sensitivity of steady-state abundance of eight species to reproduction parameter $d_{i}$ for tolerant canopy species, fixing other parameters as in Tables 1 and 2. Baseline parameter $d_{i}$ is marked by an arrow. Panels a, b, c are respectively for lag phase of 0,40 and 90 years with species parameter set given in Table 2. Shaded and open are respectively tolerant and intolerant species. The four species' stature classes of canopy, subcanopy, understory and treelet are arranged from top to bottom. No advance regeneration at gap formation. 
Fig. 5 Sensitivity of steady-state abundance of eight species to changing duration of lag phase in patch demography, $a_{\mathrm{c}}$ of Eq (3). Panels a, b, c respectively correspond to parameter sets of eight species for coexistence at 0,40 and 90 year duration of lag phase, shown in Table 2; default duration is marked by an arrow. Shaded and open are respectively tolerant and intolerant species. The four species' stature classes of canopy, subcanopy, understory and treelet are arranged from top to bottom. No advance regeneration at gap formation.

Fig. 6 Sensitivity of steady-state abundance of eight species to changing advance regeneration, $k$ of Eq (10). Panels a, b, c are respectively for lag phase of 0, 40 and 90 years with species parameter set given in Table 2. Shaded and open are respectively tolerant and intolerant species. The four species' stature classes are canopy, subcanopy, understory and treelet from top to bottom.

Fig. 7 Simulated time course of twelve species abundance in basal area for patch demography with no lag phase, using species parameters in Tables 1 and 2. Shaded, hutched and open are respectively tolerant, subtolerant and intolerant species. The four species' stature classes, canopy, subcanopy, understory and treelet, are arranged from top to bottom for each of tolerance classes. No advance regeneration at gap formation.

Fig. 8 Sensitivity of steady-state abundance of twelve species to (a) changing duration of lag phase, $a_{\mathrm{c}}$ of Eq (3), without advance regeneration, and (b) changing advance regeneration, $k$ of $\mathrm{Eq}(10)$. Shaded, hutched and open are respectively tolerant, subtolerant and intolerant species. The four species' stature classes are canopy, subcanopy, understory and treelet from top to bottom for each tolerance class. 


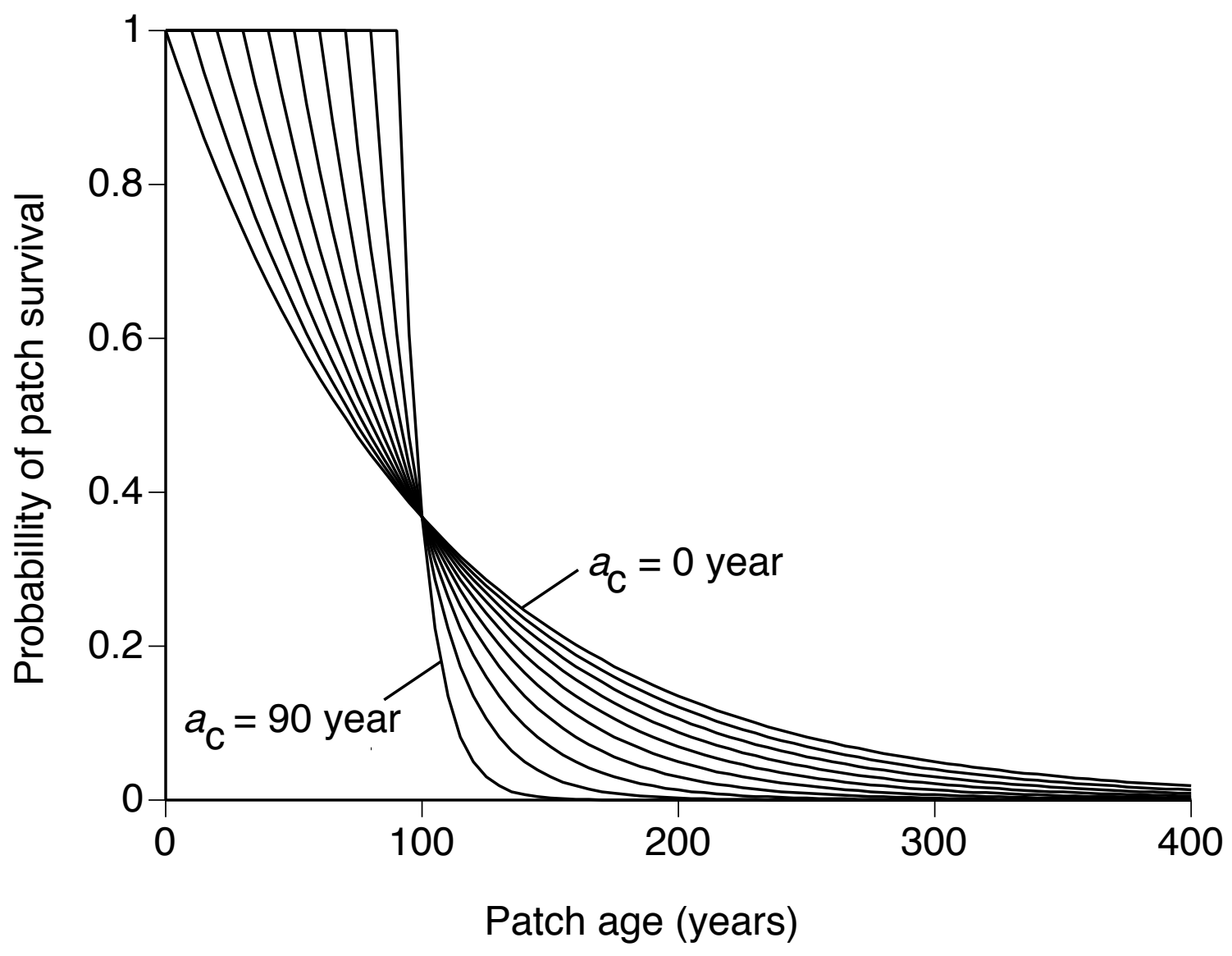

Fig 1 


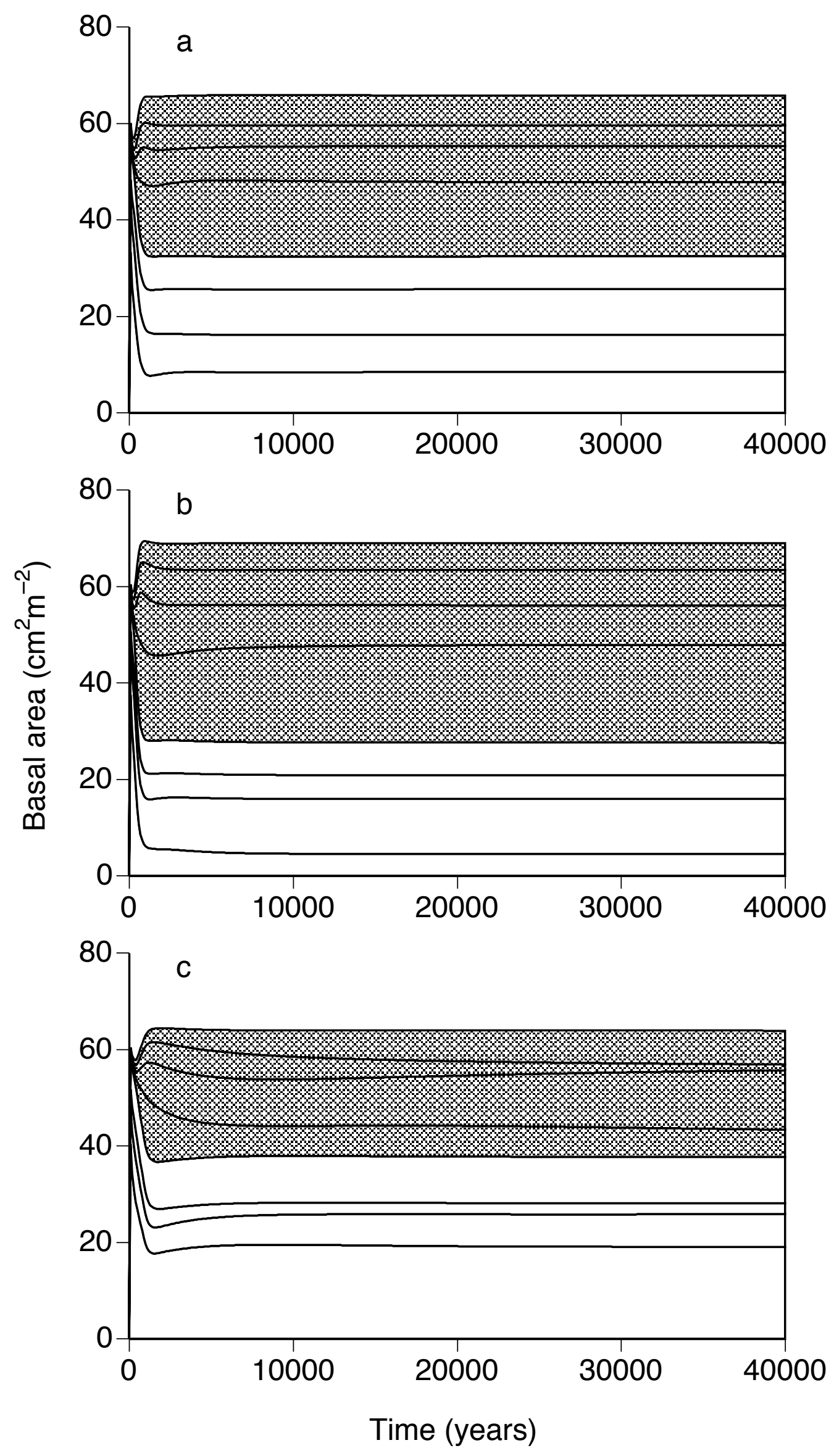

Fig 2 


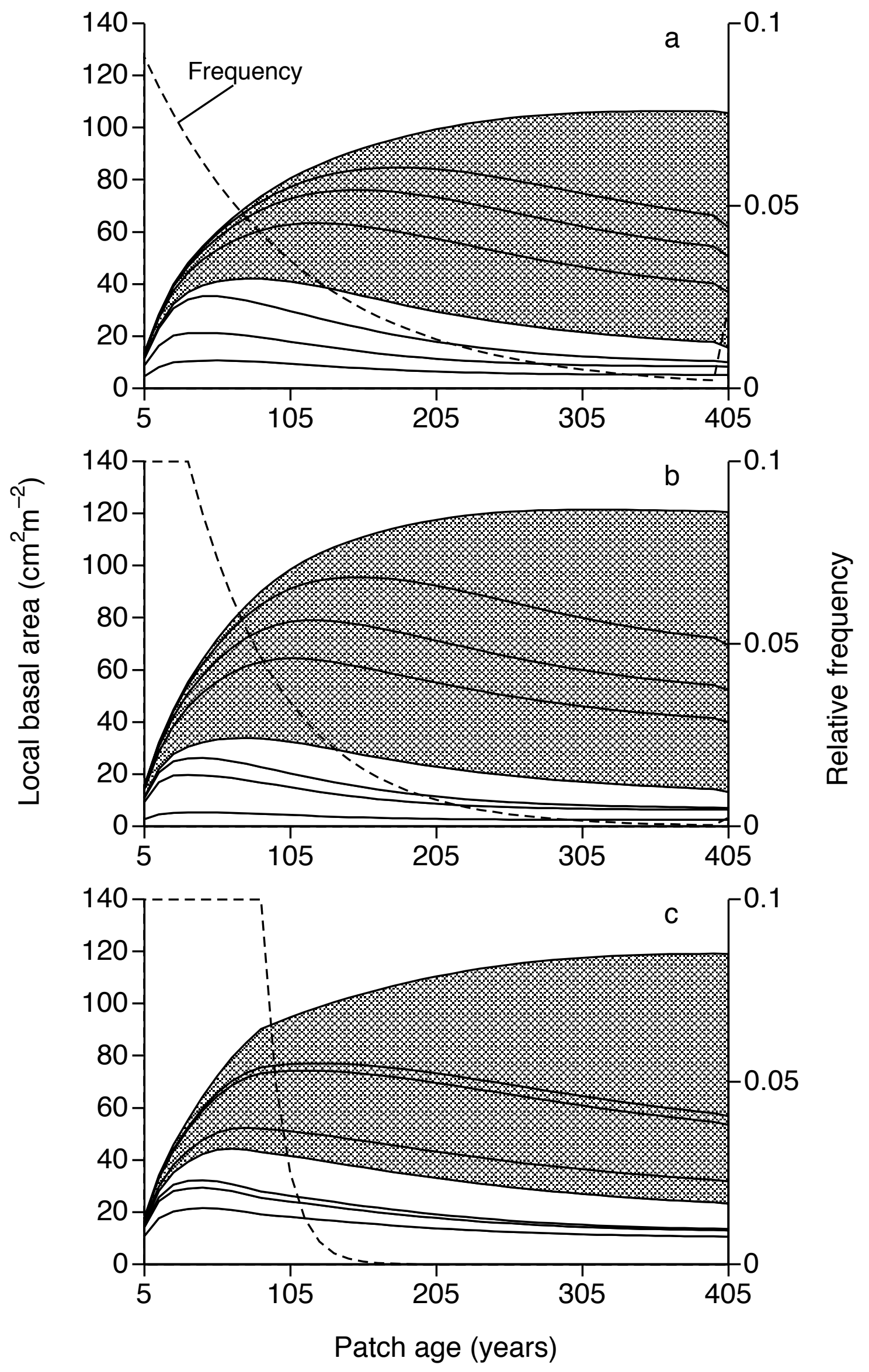

Fig 3 


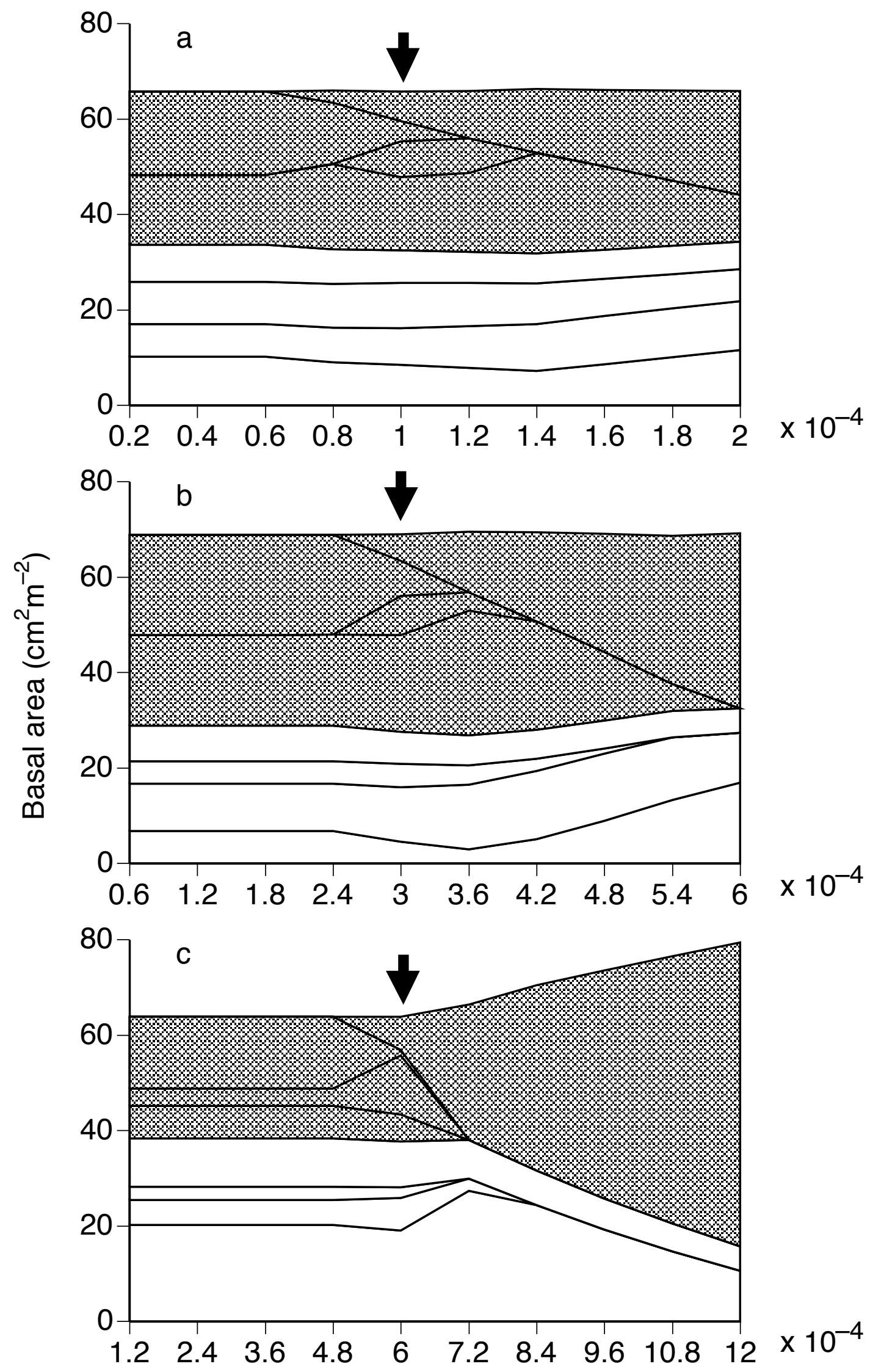

Reproduction parameter $d_{i}$ for tolerant canopy species

Fig 4 


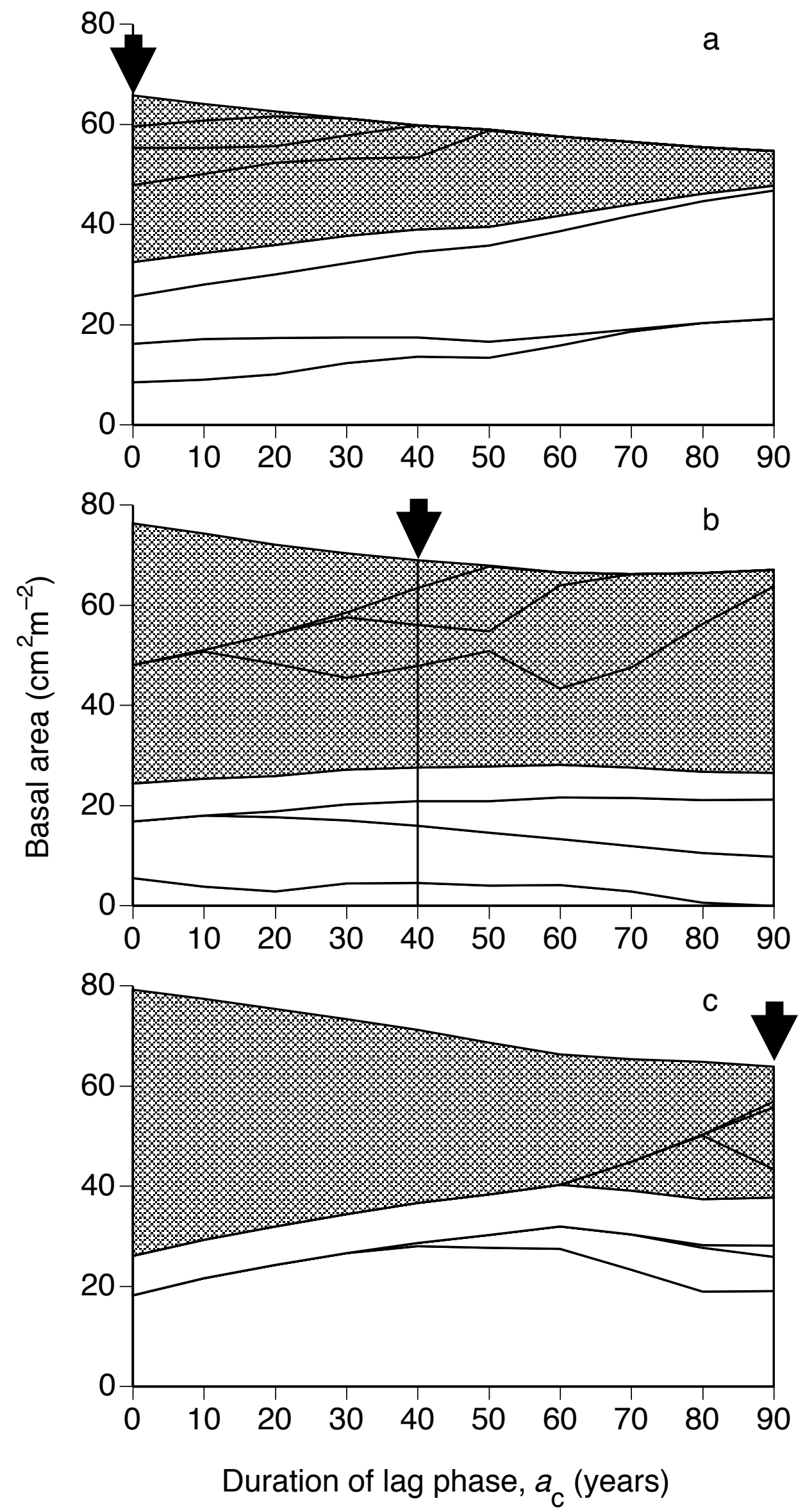

Fig 5 

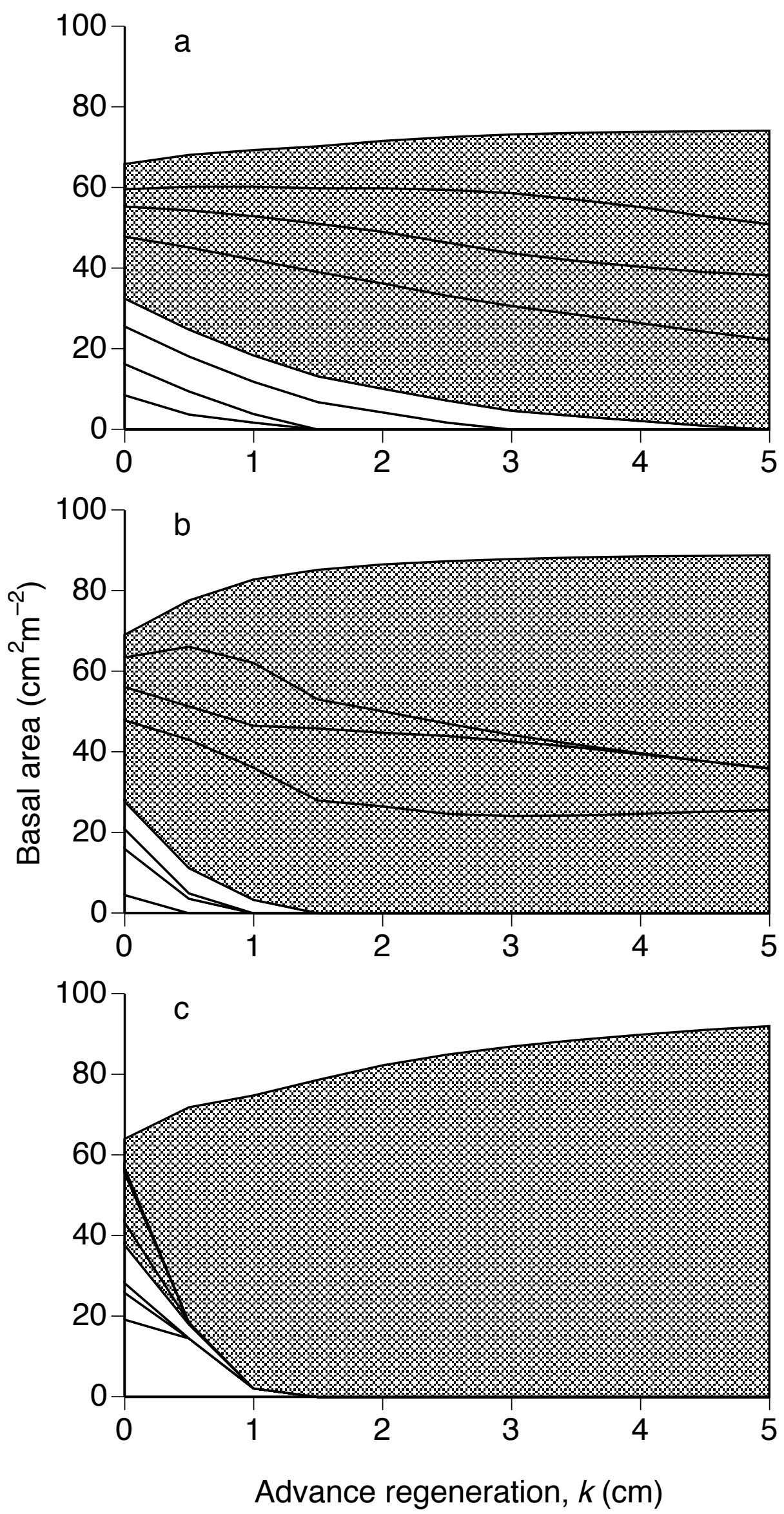

Fig 6 


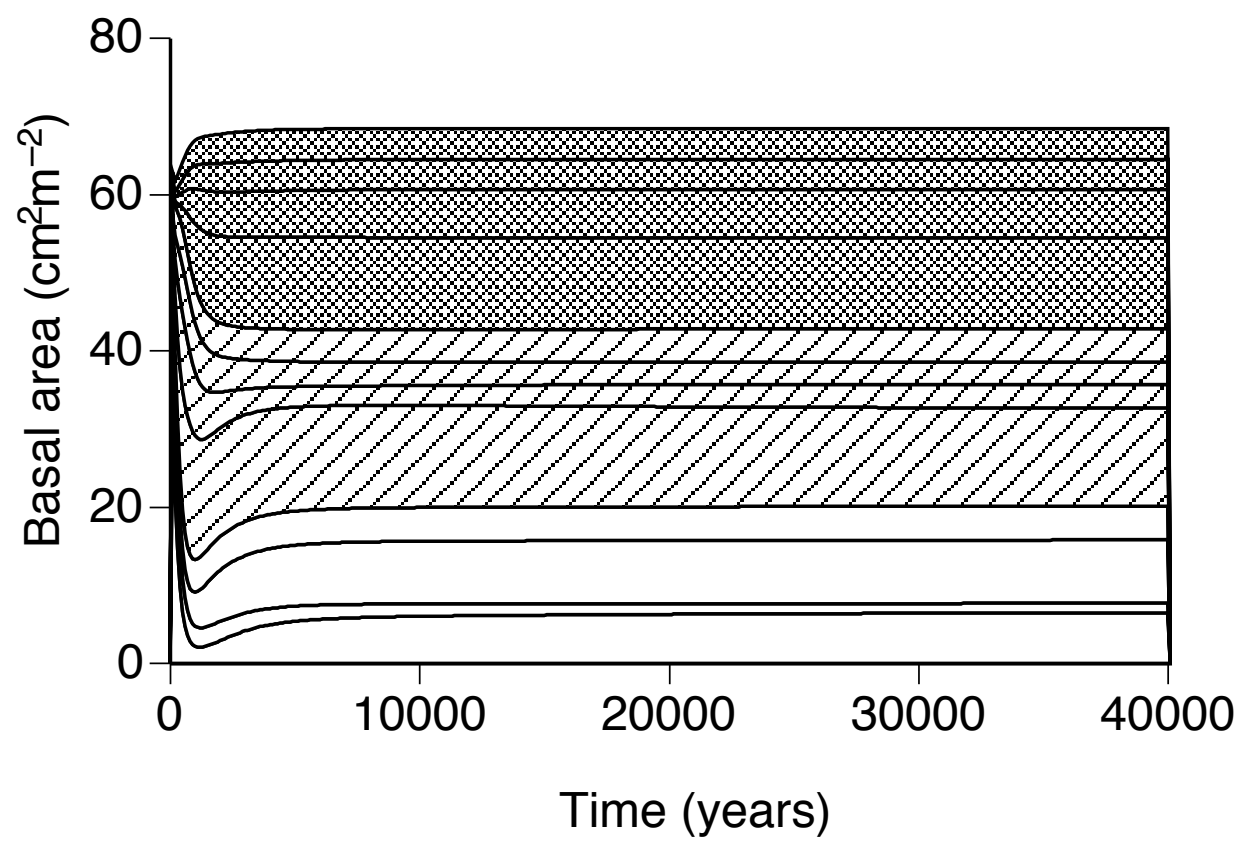

Fig 7 

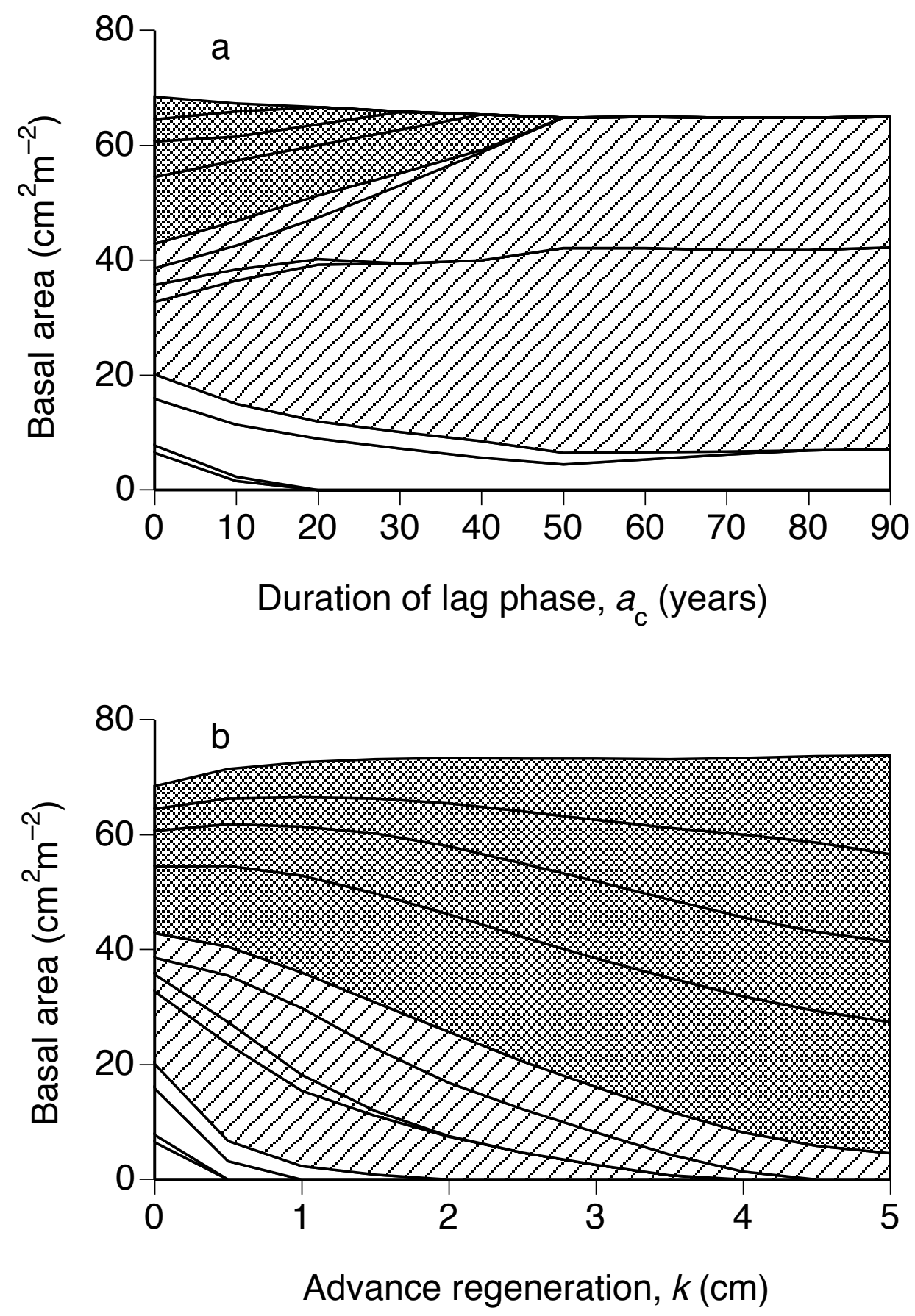

Fig 8 